\title{
Methods and applications for ecological vulnerability evaluation in a hyper-arid oasis: a case study of the Turpan Oasis, China
}

\author{
Huan Pei · Shifeng Fang $\cdot$ Lu Lin $\cdot$ Zhihao Qin · \\ Xiaoyan Wang
}

Received: 13 August 2014/ Accepted: 30 January 2015/Published online: 12 February 2015

(C) Springer-Verlag Berlin Heidelberg 2015

\begin{abstract}
The Turpan Oasis is a typical fragile environment that lies in an arid region of eastern Xinjiang and is affected by natural conditions and human activities. The severity of the land degradation and desertification in this area is increasing; therefore, ecological vulnerability evaluations are important for environmental management of the region. In this study, theories and methods of evaluating ecological vulnerability and the typical characteristics of ecological vulnerability were summarized. By combining the environmental characteristics of the research area and the driving factors of ecological vulnerability, a multilayer vulnerability evaluation index system was built, and a pressure-state-response model was established to evaluate the ecological vulnerability. GIS and remote sensing technologies were applied to extract each index and create a spatial distribution map of
\end{abstract}

H. Pei $\cdot$ X. Wang

College of Information Science and Engineering, Yanshan

University, Qinhuangdao, China

S. Fang $(\bowtie)$

LREIS, Institute of Geographic Sciences and Natural Resources Research, Chinese Academy of Sciences, Room 1427, 11A Datun Road, Chaoyang District, Beijing 100101, China e-mail: fsfno1@163.com

S. Fang

Xinjiang Academy of Environmental Protection Science, Urumqi, China

L. Lin

Department of Geography and Resource Management, The Chinese University of Hong Kong, Hong Kong, China

Z. Qin

Institute of Agro-Resources and Regional Planning, Chinese Academy of Agricultural Sciences, Beijing, China vulnerability. The results showed that the vulnerability index values ranged from 3.08 to 6.59 , with an average value of 5.19. Regions with moderate vulnerability accounted for $81.85 \%$ of the total area, whereas regions with light and serious vulnerability accounted for 4.19 and $13.95 \%$ of the total area, respectively. Thus, more than $80 \%$ of the area had moderate vulnerability, and nearly $14 \%$ of the area had serious vulnerability. The degree of vulnerability increased from east to west, and the ecological vulnerability in the inner oasis was significantly lower than that in the outer oasis. The key factors for ecological restoration and reconstruction are to control desertification and to ensure ecological water use to the greatest extent.

Keywords Ecological environment - Vulnerability · Desertification · Index system · Turpan Oasis

\section{Introduction}

The research on ecological vulnerability involves financial systems (Benjamin et al. 2013; Zou et al. 2013), disaster systems (Fuchs et al. 2012; Lashkari and Bannayan 2012), climate changes (Moreno and Becken 2009; Yoo et al. 2011), and watershed ecological systems (Ippolito et al. 2010; Shao et al. 2014; Wan et al. 2014). The concept of a vulnerable ecological environment was developed from the study of ecotones, and it has been defined by multiple researchers from different disciplines. Watts and Bohle (1993) postulated that vulnerability is the degree of negative responses that occur after a disaster event. Hufschmidt (2011) considered vulnerability to be the ability to prevent natural disasters and self-recovery. From these expressions of ecological vulnerability, three implications can be 
derived: the ecological system is inherently unstable, the system is sensitive to interference and environmental change, and the system is vulnerable with difficulties in recovery.

The study of ecological vulnerability mainly focuses on two aspects, namely the evaluation of vulnerability and its causes. The evaluation of ecological vulnerability is one of the most important aspects of ecological research, and its goal is to obtain knowledge regarding vulnerable systems and the evolution of global ecological environments. The evaluation of ecosystem vulnerability is important not only for ecological construction guidance and maintenance but also for land management and the rational use of resources (Sullivan 2011; Manfre et al. 2013). The successful implementation of a restoration project requires analysis of the present conditions of the ecological environment and its evolving trends (Aspinall and Pearson 2000; Santos et al. 2013). Moreover, ecological vulnerability evaluations can be combined with ecological security, pollution management, disaster resistance and insurance, and also provide a theoretical basis and reference for the development of the regional environment. Ecological vulnerability evaluation has developed rapidly in recent years, and many theories and methods have been proposed, such as the multi-index comprehensive evaluation method (Zhou et al. 2011; Duguy et al. 2012), the fuzzy evaluation method (Farshad et al. 2013; Aryafar et al. 2013), the artificial neural network evaluation method (Dzeroski 2001; Kia et al. 2012), the landscape evaluation method (Kangas et al. 2000; Antonio et al. 2003; Salvati et al. 2013), the analytic hierarchy process (AHP) method (Huang et al. 2010; Song et al. 2010), and the principal component analysis method (Khan 2012). GIS and remote sensing technologies have become powerful tools for index acquisition and spatial distribution mapping for ecological vulnerability studies (Babiker et al. 2005; Saidi et al. 2010; Bagdanavičiūtè and Valiūnas 2013). The establishment of index systems is a key step for such evaluations. Recently, a series of index systems were created for different ecosystem types. For example, Li et al. (2006) used a spatial principal component analysis method and selected nine indexes to evaluate the vulnerability of the Minjiang River. These indexes included natural and social factors, such as elevation, slope, accumulated temperature, drought index, vegetation, soil, water-soil erosion, land use, and population density. Scheuer et al. (2011) modeled flood vulnerability by integrating economic, social, and ecological indicators of hazard and response capacity such as residential buildings, land value per floor space, and affected population. The indexes used for the assessment of vulnerability in the oasis usually involve vegetation coverage, landscape fragmentation, desertification sensitivity, soil salinization, grazing capacity, population, and economic pressures.
Desertification degree is an important index in the study of vulnerability in the oasis (Gao et al. 2013; Mao et al. 2013). The existing studies demonstrate two key points in vulnerability assessment. One point is how to choose the indexes, and the other is how to assign a weight to each index. Different ecosystems have different characteristics, and the indexes that reflect ecological vulnerability change are very complex. Therefore, there is no uniform standard in choosing vulnerability assessment indexes and the index system should be indicative, operational, and representative. Regarding the choice of weight, there are many methods to determine the weight of each index listed above. AHP is the most widely used method; however, artificial neural network and fuzzy comprehensive evaluation methods are also widely applied, which reduce the subjective judgment of weight assignment.

The oasis is an important type of ecosystem in China, and because it is a complex and specific natural environment, it is particularly sensitive to outside interference. As human activity has increased, the environmental problems in the oasis have become increasingly prominent. The Turpan Oasis in east Xinjiang was chosen for this study because it is an important section of the vulnerable arid oasis region of China. It is suitable for farming and animal husbandry because of its abundant land resources and high levels of light and heat. However, interference from human activities has intensified its ecological vulnerability, which is gradually becoming more serious. Desertification and particularly salinization have become the most serious ecological problems. These issues have had an important influence on the economic development of the region and even on the livelihood of the local population. Thus, it is an important region for ecological restoration in China. The main objective of this study was to provide a feasible method for studying the ecological vulnerability of the oasis and to determine the typical environmental vulnerability characteristics of arid regions. The results can provide suggestions for the sustainable development and reconstruction of environments in hyper-arid areas.

\section{Study region}

The Turpan Oasis is located in the hyper-arid region of eastern Xinjiang and is a typical arid oasis with strong ecological vulnerability and sensitivity. It lies between $31-33^{\circ} \mathrm{N}$ and $102-104^{\circ} \mathrm{E}$ and has an area of approximately $69,713 \mathrm{~km}^{2}$. The topography of the Turpan Oasis is characterized by an interlaced distribution of hills and plains and ranges in elevation from -155 to $3,600 \mathrm{~m}$. Influenced by the Tarim thermal depression and strong solar radiation, it has a climate with particularly high temperatures, extended hot periods, and frequent strong winds. The Turpan 
Oasis is very dry, with an average annual rainfall of only 6.9-25.2 $\mathrm{mm}$; the evaporation is extremely strong, with an average evaporation capacity of 2,727-3,837.8 mm, which is $110-540$ times higher than the average rainfall. At present, desertification, and particularly salinization, have become the most serious ecological problems and have already negatively influenced the local economic development. The study area is located northwest of the Turpan region and consists of 14 towns. Figure 1 shows the relationship between the study area and the Turpan Oasis.

\section{Methodology}

Study data

The basic data used in this study include the following: (1) SPOT-5 data (October 2004), with a resolution of $10 \mathrm{~m}$; (2)
70 topographic maps at a scale of 1:50,000 that cover 14 towns in the study area; (3) a map of soil type, ground water level, and water quality monitoring data; and (4) socioeconomic statistics such as the population and GDP for each town. SPOT-5 data were corrected based on topographic maps and matched to form a mosaic image. A digital elevation model (DEM) was built from the vectorized contour line and resampled to a $10-\mathrm{m}$ resolution. The decision tree classification method was used to extract the land use and land cover information, particularly for the desertification information.

The overall technology course of the study

The selection of evaluating indexes plays an important role in evaluating the regional ecological vulnerability. First, the ecological vulnerability evaluation index system was built. Using remote sensing and GIS technologies, SPOT-5
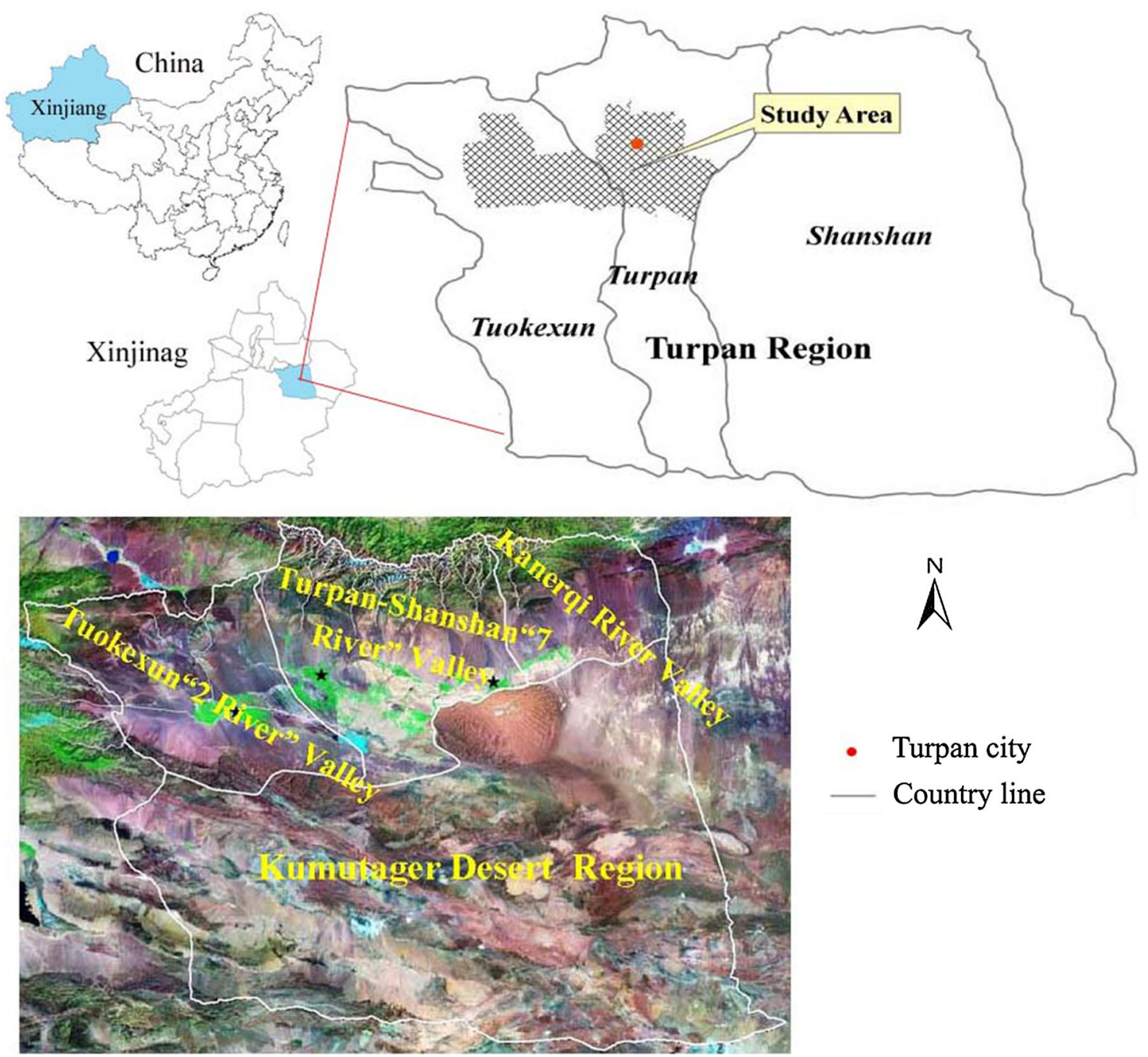

- Turpan city

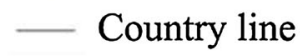

Fig. 1 Administrative and remote sensing map of the Turpan region, and the relationship between the study area and the Turpan Oasis 
data (10 m resolution) were used to abstract land use, vegetation, and other indexes. The DEM was built from contour lines and added to the SPOT-5 images as a spatial feature to aid in classification. Second, an AHP and comprehensive evaluation method were combined to evaluate the ecological pressure, ecological sensitivity, ecological stability, and comprehensive vulnerability. The spatial distribution of vulnerability and its driving factors were then analyzed. Finally, the ecological restoration and reconstruction strategies were introduced according to the vulnerability evaluation results. Figure 2 shows the steps of the research.

Remote sensing image classification and desertification information extraction

Land use and land cover information, particularly desertification information, is an essential aspect of ecological vulnerability evaluations that indicate ecological pressures. Therefore, a classification system should be constructed, and a suitable classification method should be selected to acquire land use and desertification information. There are several desertification types in the Turpan Oasis, such as vegetation degradation, wind erosion, and salinization (Fang et al. 2010). In this study, the land of the study area was classified into two main categories, namely desertification and non-desertification. Non-desertification is divided into six types, including water bodies, AiDing Lake, urban land, cultivated land, garden and forest lands, and grasslands. Desertification is divided into four types, including saline land, mild wind erosion desertification, moderate wind erosion desertification, and serious wind erosion desertification. Among the desertification types, mild desertification was characterized by an in situ sand

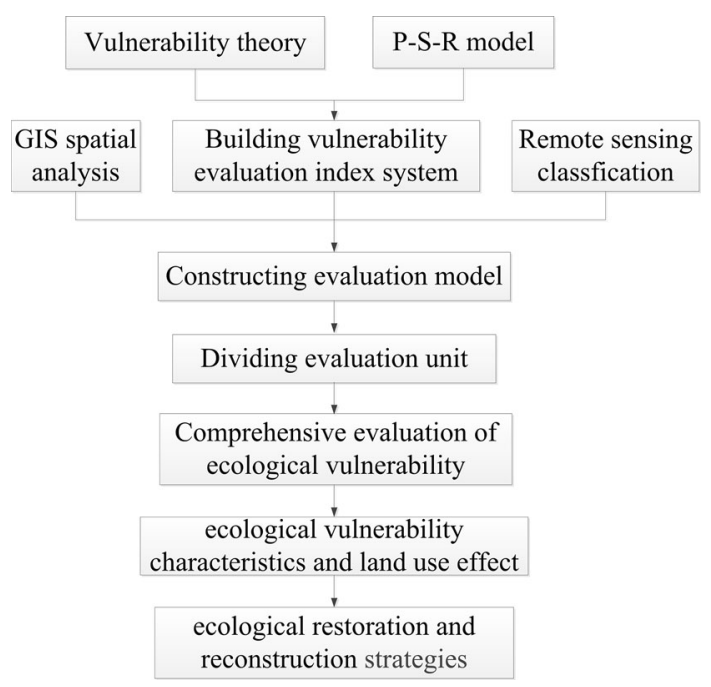

Fig. 2 The technique flow chart of the study source and had a tendency of desertification; moderate desertification indicated wind monadnocks, dunes, halfnaked gravel, and bare grasslands; and serious desertification referred to desert with no vegetation. According to the land use and land cover classification system, the decision tree classification method was adopted to extract the land use and land cover information.

Establishment of the ecological vulnerability index system

According to the ecological vulnerability concept defined by the author and the regional ecological problems, 16 indicators, including the desertification index, ground water level, and population density, considered to be the most critical in the study area were selected. The selected vulnerability indicators can be grouped into three broad classes: ecological (natural and social) pressure, ecological sensitivity, and ecological stability.

\section{Ecological pressure indexes}

Ecological pressure includes natural and social pressure. In this paper, indexes representing population, environment, and social economic pressure were selected. The calculation methods for part of the indexes are listed below.

Population density $\left(\mathrm{A}_{11}\right)$ : A large part of the area in an arid region is desert; therefore, it is unreasonable to calculate the population density by dividing the regional population by the area. The desert area should be deducted. According to the classification system, the desertification area is removed from the total area of each evaluation unit.

Desertification index $\left(\mathrm{A}_{21}\right)$ : Desertification is the direct response of the ecological environment to human activity and has brought many adverse effects to local human populations. In this study, the desertification index is defined as the ratio of the desertification area to the total area of each evaluation unit.

Salinization index $\left(\mathrm{A}_{22}\right)$ : In this study, the land salinization index is defined as the ratio of the salinization area to the total area of each evaluation unit.

Land use degree index $\left(\mathrm{A}_{32}\right)$ : The land use degree represents the degree of human damage to the land. The dimensionless standard for land use degree is listed in Table 1.

Ecological sensitivity indexes

The most serious ecological environment problems in the Turpan Oasis are desertification and salinization. The occurrence of wind erosion desertification is more sensitive to 
Table 1 Quantitative grading of the land use degree indexes

\begin{tabular}{lllllll}
\hline $\begin{array}{l}\text { Land } \\
\text { use type }\end{array}$ & Water & $\begin{array}{l}\text { Forested land, } \\
\text { farmland, } \\
\text { artificial land }\end{array}$ & $\begin{array}{l}\text { High } \\
\text { cover } \\
\text { grass }\end{array}$ & $\begin{array}{l}\text { Woodland, } \\
\text { spinney, middle } \\
\text { cover grass }\end{array}$ & $\begin{array}{l}\text { Non-forested } \\
\text { land, low cover } \\
\text { grass }\end{array}$ & $\begin{array}{l}\text { Saline-alkali land, } \\
\text { industrial and } \\
\text { unused land }\end{array}$ \\
\hline Index & 0 & 2 & 4 & 6 & 8 & 10 \\
\hline
\end{tabular}

climate dryness, wind, and soil texture, whereas salinization is related to the groundwater level, soil types, and evaporating capacity (Chatterjee et al. 2014).

Dryness $\left(B_{11}\right)$ : Based on the existing research (Shi et al. 2010), dryness is calculated as follows:

$B_{11}=\frac{0.16 \sum t}{r}$

where $\sum t$ is the sum of average daily air temperatures exceeding $10{ }^{\circ} \mathrm{C}$ and $r$ is the precipitation for the same period.

The observed temperature and precipitation values from 18 weather stations were collected and the dryness was obtained. Then the dryness was interpolated to obtain raster data of the study area.

Soil texture $\left(\mathrm{B}_{13}\right)$ : Combining the findings of existing studies (Li et al. 2006), a standardized score of desertification sensitivity for different soil textures was produced (Table 2).

Ground water level $\left(\mathrm{B}_{21}\right)$ : The groundwater levels at 32 existing wells were collected and these data were imported into the ArcGIS software based on their geographical coordinates to produce the point layer of the groundwater level. Based on the kriging interpolation algorithm, a groundwater level map was constructed (Fig. 3).

Soil types $\left(\mathrm{B}_{22}\right)$ : Based on the relevant research (Bi et al. 2013) the standardized score to different soil types was assigned with the following results (see Table 3).

\section{Ecological stability indexes}

Ecological stability can be evaluated according to the structure, function, vitality, and elasticity of the system (Tasser et al. 2008; Walz and Syrbe 2013; Walz 2015); in this paper, the landscape diversity index, soil organic matter, surface water resources per unit, biological abundance, and vegetation coverage were selected to reflect these four indexes.

Table 2 Quantitative grading for soil texture in the desertification sensitivity index

\begin{tabular}{llllll}
\hline $\begin{array}{l}\text { Soil } \\
\text { texture }\end{array}$ & $\begin{array}{l}\text { Matrix } \\
\text { soil }\end{array}$ & $\begin{array}{l}\text { Clay } \\
\text { soil }\end{array}$ & $\begin{array}{l}\text { Gravelly } \\
\text { soil }\end{array}$ & $\begin{array}{l}\text { Loamy } \\
\text { soil }\end{array}$ & $\begin{array}{l}\text { Sandy } \\
\text { soil }\end{array}$ \\
\hline Index & 1 & 3 & 5 & 7 & 9 \\
\hline
\end{tabular}

Landscape diversity index $\left(C_{11}\right)$ : In general, when the component of a system is more complex, it will be more stable. Landscape diversity can be calculated as follows (Ramezani and Holm 2011):

$C_{11}=-\sum_{\mathrm{i}=1}^{\mathrm{n}}\left(P_{i} \times \ln P_{i}\right)$

where $P_{i}$ is the proportion of $i$ landscape area and $n$ is the number of landscape types.

Soil organic matter $\left(\mathrm{C}_{21}\right)$ : According to relevant studies (Wang et al. 2008), a standardized score to different organic matter contents was obtained (Table 4).

Biological abundance index $\left(C_{31}\right)$ : The biological abundance index can indirectly reflect the biomass in an evaluation unit and can be calculated as follows:

$C_{31}=(0.35 \times$ forest $\quad$ area $+0.21 \times$ grassland + $0.28 \times$ water area $+0.11 \times$ farmland $+0.04 \times$ construction land $+0.01 \times$ unused land)/unit area.

Vegetation coverage $\left(C_{41}\right)$ : Vegetation coverage can reflect the production capability of a natural system and can be calculated as follows:

$C_{41}=\frac{\mathrm{NDVI}-\mathrm{NDVI}_{\min }}{\mathrm{NDVI}_{\max }-\mathrm{NDVI}_{\min }}$

where NDVI is the normalization vegetation index and $\mathrm{NDVI}_{\text {min }}$ and $\mathrm{NDVI}_{\text {max }}$ are the values of NDVI for the bare ground and fully vegetated ground, respectively, in the evaluation area.

The specification of indexes used in the vulnerability framework is presented in Table 5 .

Evaluation model

Except for the land use degree index, desertification sensitivity index, salinization sensitivity index, and soil organic content, which were assigned standard values as described above, all other indexes were standardized to have the same dimensions by the maximum and minimum value standardization methods. The AHP method was used to determine the index weight. Then the ecological vulnerability evaluation model was constructed from the weighted summation of ecological stability, ecological sensitivity, and ecological pressure for the data from the three partial target levels.

$\mathrm{EVI}=\sum_{i=1}^{3} F_{i} \times W_{i}$ 
Fig. 3 The groundwater level map of the study area

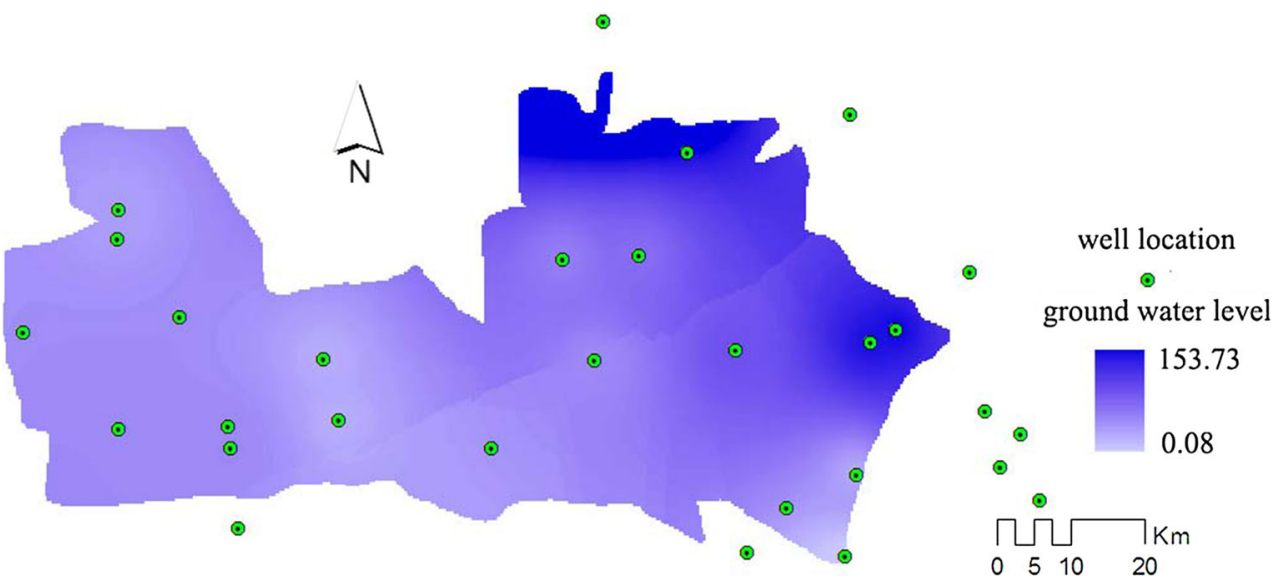

Table 3 Quantitative grading for soil types in the salinization sensitivity index

\begin{tabular}{llllll}
\hline $\begin{array}{l}\text { Soil } \\
\text { type }\end{array}$ & $\begin{array}{l}\text { Rocky } \\
\text { soil }\end{array}$ & $\begin{array}{l}\text { Brown } \\
\text { desert soil }\end{array}$ & $\begin{array}{l}\text { Sandy } \\
\text { soil }\end{array}$ & $\begin{array}{l}\text { Irrigated } \\
\text { silting soil }\end{array}$ & $\begin{array}{l}\text { Saline } \\
\text { soil }\end{array}$ \\
\hline Index & 0 & 2 & 3 & 7 & 9 \\
\hline
\end{tabular}

Table 4 Quantitative grading for soil organic content

\begin{tabular}{llllll}
\hline Soil organic content $(\%)$ & $>1.5$ & $1.0-1.5$ & $0.8-1$ & $0.6-0.8$ & $<0.6$ \\
\hline Index & 2 & 4 & 6 & 8 & 10 \\
\hline
\end{tabular}

$F_{i}=\sum_{i=1}^{n} I_{i} \times P_{i}$

In this formula, EVI is the ecological vulnerability index; $F_{i}$ represents the value of the ecological sensitivity, ecological stability, and ecological pressure; $W_{i}$ is the weight of sensitivity, stability, and pressure; $I_{i}$ is the standard value of the indexes representing ecological sensitivity, ecological stability, and ecological pressure; and $P_{i}$ is the weight of the corresponding indexes.

\section{Evaluation unit}

In this study, the vector evaluation unit and the raster $(10 \times 10 \mathrm{~m})$ evaluation unit were combined for vulnerability analysis. The initial value of each grid for several indexes, such as the biological abundance index, could not be directly obtained; therefore, the administrative border of each town was used as the evaluation unit, and the mean value of the index was calculated to represent the value of all grids in the town.

\section{Vulnerable gradation}

The result calculated from the EVI model is a continuous value that should be sorted into several grades representing the different levels of ecological vulnerability. Combining the existing research results with the natural conditions of the Turpan Oasis and the ecological system vulnerability characteristics, vulnerability was divided into five grades, with each grade corresponding to one section of the ecological vulnerability index (EVI). The results are listed in Table 6.

\section{Results}

Results for land use and land cover classification

The map of land use was obtained according to the classification method introduced in the methodology section, as shown in Fig. 4. In total, 1,000 points were selected from stratified sampling, and the precision of the classification result was tested according to the topographical map and visual interpretation. Table 7 is the accuracy report of the classification. It showed that both the producer's accuracy and the user's accuracy are above 0.8 for all land use types except saline land. This exception occurs because the spectral value of saline land is similar to those of moderate wind erosion and grasslands, and it is difficult to differentiate them accurately. The total classification precision is $87.9 \%$, and the classification accuracy meets the application requirements.

The desertification area was $3,990.55 \mathrm{~km}^{2}$ in 2004 and accounted for $80.88 \%$ of the total area. Wind erosion desertification was the main desertification type in the study area and accounted for $64.05 \%$ of the total area; it was mainly distributed on the edge and periphery of the oasis and was composed of gravel and naked rock. Mild wind erosion desertification was mainly distributed in the inner part of the oasis and accounted for $7.58 \%$ of the total area; it was formed by the degradation of natural grasslands, with part of the land exhibiting badly weathered characteristics. Serious wind erosion desertification 
Table 5 Ecological vulnerability evaluation index for the Turpan Oasis

\begin{tabular}{|c|c|c|c|c|c|c|}
\hline Target level & $\begin{array}{l}\text { Partial target } \\
\text { level }\end{array}$ & $\begin{array}{l}\text { Layer } \\
\text { weight }\end{array}$ & Rule layer & $\begin{array}{l}\text { Rule layer } \\
\text { weight }\end{array}$ & Index layer & $\begin{array}{l}\text { Index layer } \\
\text { weight }\end{array}$ \\
\hline \multirow{16}{*}{$\begin{array}{l}\text { Ecological environment } \\
\text { vulnerability }\end{array}$} & \multirow[t]{5}{*}{ Pressure (A) } & \multirow[t]{5}{*}{0.31} & Population pressure $\left(\mathrm{A}_{1}\right)$ & 0.24 & Population density $\left(\mathrm{A}_{11}\right)$ & 1 \\
\hline & & & \multirow[t]{2}{*}{ Environment pressure $\left(\mathrm{A}_{2}\right)$} & \multirow[t]{2}{*}{0.36} & Desertification index $\left(\mathrm{A}_{21}\right)$ & 0.6 \\
\hline & & & & & Salinization index $\left(\mathrm{A}_{22}\right)$ & 0.4 \\
\hline & & & \multirow{2}{*}{$\begin{array}{l}\text { Social economic pressure } \\
\left(\mathrm{A}_{3}\right)\end{array}$} & \multirow[t]{2}{*}{0.4} & Per capita GDP $\left(\mathrm{A}_{31}\right)$ & 0.55 \\
\hline & & & & & Land use degree index $\left(\mathrm{A}_{32}\right)$ & 0.45 \\
\hline & \multirow[t]{6}{*}{ Sensitivity (B) } & \multirow[t]{6}{*}{0.23} & \multirow{3}{*}{$\begin{array}{l}\text { Desertification sensitivity } \\
\left(\mathrm{B}_{1}\right)\end{array}$} & \multirow[t]{3}{*}{0.5} & Dryness $\left(\mathrm{B}_{11}\right)$ & 0.29 \\
\hline & & & & & Average wind speed $\left(B_{12}\right)$ & 0.33 \\
\hline & & & & & Soil texture $\left(\mathrm{B}_{13}\right)$ & 0.38 \\
\hline & & & \multirow[t]{3}{*}{ Salinization sensitivity $\left(B_{2}\right)$} & \multirow[t]{3}{*}{0.5} & Ground water level $\left(B_{21}\right)$ & 0.53 \\
\hline & & & & & Soil type $\left(\mathrm{B}_{22}\right)$ & 0.21 \\
\hline & & & & & Evaporating capacity $\left(\mathrm{B}_{23}\right)$ & 0.26 \\
\hline & \multirow[t]{5}{*}{ Stability (C) } & \multirow[t]{5}{*}{0.46} & Structure $\left(\mathrm{C}_{1}\right)$ & 0.25 & $\begin{array}{l}\text { Landscape diversity } \\
\text { index }\left(\mathrm{C}_{11}\right)\end{array}$ & 1 \\
\hline & & & \multirow[t]{2}{*}{ Function $\left(\mathrm{C}_{2}\right)$} & \multirow[t]{2}{*}{0.25} & Soil organic matter $\left(\mathrm{C}_{21}\right)$ & 0.5 \\
\hline & & & & & $\begin{array}{l}\text { Per unit surface water } \\
\text { resources }\left(C_{22}\right)\end{array}$ & 0.5 \\
\hline & & & Vitality $\left(\mathrm{C}_{3}\right)$ & 0.25 & Biological abundance $\left(\mathrm{C}_{31}\right)$ & 1 \\
\hline & & & Elasticity $\left(\mathrm{C}_{4}\right)$ & 0.25 & Vegetation coverage $\left(\mathrm{C}_{41}\right)$ & 1 \\
\hline
\end{tabular}

The consistency index of each layer satisfies RI $<0.1$

Table 6 The results of ecological vulnerability classification in the Turpan Oasis

\begin{tabular}{llllll}
\hline $\begin{array}{l}\text { Comprehensive } \\
\text { evaluation grade }\end{array}$ & $\begin{array}{l}\text { Mired } \\
\text { vulnerability }\end{array}$ & $\begin{array}{l}\text { Light } \\
\text { vulnerability }\end{array}$ & $\begin{array}{l}\text { Moderate } \\
\text { vulnerability }\end{array}$ & $\begin{array}{l}\text { Serious } \\
\text { vulnerability }\end{array}$ & $\begin{array}{l}\text { Extreme } \\
\text { vulnerability }\end{array}$ \\
\hline EVI & $0-2$ & $2-4$ & $4-6$ & $6-8$ & $8-10$ \\
\hline
\end{tabular}

accounted for $2.23 \%$ of the total area and was completely covered by desert. Saline land was the other main desertification type in the study area and was mainly distributed around AiDing Lake, with the salt exposed to the surface in certain areas. The degree of desertification in the study area is very high, and the desertification has aggravated the ecological vulnerability.

\section{Results for ecological vulnerability}

According to Formula (5), the degree of ecological pressure for the entire research area and each town were calculated as shown in Table 8 . The minimum, maximum, and average pressure degree indexes were 1.12, 7.76, and 4.75, respectively. The average pressure index results (Table 8) of each town show that the average pressure indexes of AiDing, GuoLeBuYi, BoSiTan, and the 221st state farm were all higher than five. For AiDing, the average pressure index reached 7.65 , and $99.46 \%$ of the area was considered to be a serious pressure region, which is considered to represent a serious threat to the regional ecological security. Among the 14 towns, YuanZhongChang and SanBao had the lowest average pressure degree index because these two towns are located in the inner oasis and have low degrees of land use, desertification, and salinization.

The evaluation results of ecological sensitivity show that the lowest ecological sensitivity index of the study area was at YuanYiChang (2.83), and the maximum ecological sensitivity index was at XiaXiang (7.41). The average ecological sensitivity index was 6.1 . The proportion of lightly sensitive areas was $0.34 \%$, the proportion of moderately sensitive areas was $35.49 \%$, and the proportion of severely sensitive areas was $64.16 \%$. The sensitivity level in the Turpan Oasis increased from north to south. The sensitivity index of YuanYiChang, YaEr, and Turpan in the northern oasis was approximately 4-6, and the values for the other towns were between 6 and 8, indicating that they reached a high level of sensitivity. The main reason for the high sensitivity in these towns is the higher ground water level and strong evaporation, which causes serious salinization.

The stability index in the Turpan Oasis was between 2.06 and 7.6, with an average stability index of 4.98, which indicates an unstable level. The stability of the eastern region was higher than that of the western region. 
Fig.. 4 Land use and land cover classification map of the study area

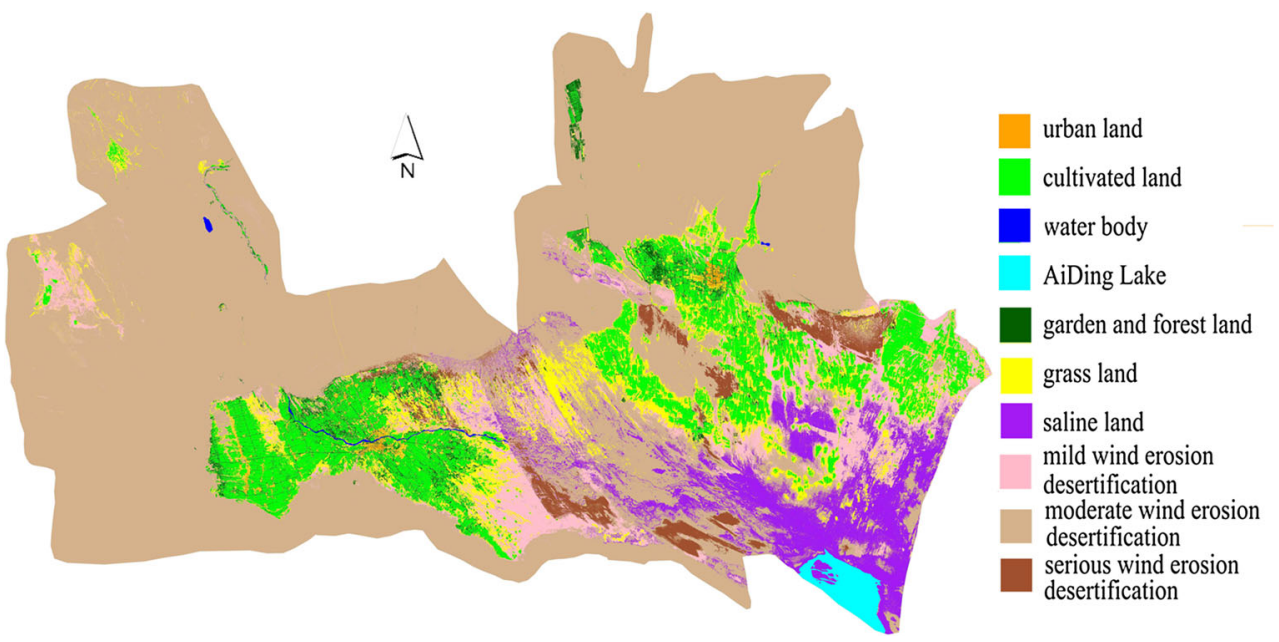

Table 7 Accuracy report of the classification in the study area

\begin{tabular}{|c|c|c|c|c|c|c|c|c|c|c|c|c|}
\hline & SL & UL & MID & MOD & SED & WB & $\mathrm{AD}$ & GF & CL & GL & Producer's accuracy & User's accuracy \\
\hline SL & 71 & 3 & 4 & 8 & 3 & 0 & 0 & 2 & 1 & 6 & 0.86 & 0.72 \\
\hline UL & 2 & 69 & 3 & 1 & 2 & 1 & 0 & 3 & 3 & 2 & 0.80 & 0.80 \\
\hline MID & 3 & 4 & 79 & 4 & 0 & 0 & 0 & 0 & 0 & 3 & 0.85 & 0.85 \\
\hline MOD & 2 & 1 & 1 & 166 & 5 & 0 & 2 & 0 & 0 & 5 & 0.91 & 0.91 \\
\hline SED & 1 & 1 & 1 & 1 & 58 & 0 & 0 & 1 & 0 & 0 & 0.85 & 0.92 \\
\hline WB & 0 & 2 & 0 & 0 & 0 & 50 & 0 & 3 & 0 & 0 & 0.98 & 0.91 \\
\hline $\mathrm{AD}$ & 0 & 0 & 0 & 0 & 0 & 0 & 36 & 0 & 0 & 0 & 0.95 & 1.00 \\
\hline GF & 0 & 2 & 0 & 0 & 0 & 0 & 0 & 111 & 7 & 1 & 0.87 & 0.92 \\
\hline CL & 1 & 0 & 3 & 1 & 0 & 0 & 0 & 5 & 148 & 1 & 0.91 & 0.93 \\
\hline GL & 3 & 4 & 2 & 2 & 0 & 0 & 0 & 2 & 3 & 91 & 0.83 & 0.85 \\
\hline Total & 83 & 86 & 93 & 183 & 68 & 51 & 38 & 127 & 162 & 109 & & \\
\hline
\end{tabular}

$W B$ is water body, $A D$ is AiDing Lake, $G F$ is garden and forest land, $C L$ is cultivated land, $G L$ is grassland, $U L$ is urban land, $S L$ is saline land, $M I D$ is mild wind erosion desertification, $M O D$ is moderate wind erosion desertification, $S E D$ is serious wind erosion desertification

Comprehensive stability was poorer in KeErJian, GuoLeBuYi, BoSiTan, and YiLaHu, which are four towns in the western oasis with an average stability index higher than six as a result of desert gravel soil, a soil organic content of 0.3 , and a diversity index only one-third that of the other regions. However, four towns in the southeast similar to QiaTeKeLe had relatively high vegetation coverage and landscape diversity, and the average stability index was approximately 3.3. In general, most areas of the oasis are in an unstable state, and it is important to improve the restoration of the ecological environment.

The ecological sensitivity index, stability index, and pressure index were overlaid according to their corresponding weights to produce an ecological vulnerability index. The characteristics of ecological vulnerability in the Turpan Oasis are concluded as follows:

1. The Turpan Oasis presents strong ecological vulnerability. The maximum vulnerability index is 6.59 , in BoSiTan, and the minimum value is 3.08 , in SanBao. The average ecological vulnerability index of the entire region is 5.19, which indicates a moderate vulnerability level. The moderate vulnerability region accounts for $81.85 \%$ of the total area, and the light and serious vulnerability regions account for 4.19 and $13.95 \%$, respectively, of the total area. More than $80 \%$ of the area has moderate vulnerability, and nearly $14 \%$ of the area has serious vulnerability. Although no extreme vulnerability regions were observed, the environmental quality is still not favorable.

2. The spatial distribution characteristics of ecological vulnerability are indicated by two aspects: the vulnerability degree increases from east to west (Fig. 5) and is significantly lower in the inner oasis than in the outer oasis. Scarce vegetation, intense evapotranspiration, strong winds, and erosion in the outer oasis have resulted in serious ecological vulnerability. 
Table 8 Average ecological pressure, sensitivity, stability, and vulnerability index in each town

\begin{tabular}{lllll}
\hline Town & Pressure index & Sensitivity index & Stability index & $\begin{array}{l}\text { Ecological vulnerability } \\
\text { index }\end{array}$ \\
\hline ErBao & 4.54 & 6.06 & 3.39 & 4.35 \\
Turpan & 4.45 & 5.41 & 4.27 & 4.58 \\
KeErJian & 4.19 & 5.89 & 6.68 & 5.72 \\
GuoLeBuYi & 5.94 & 6.38 & 6.01 & 6.07 \\
AiDing & 7.65 & 6.87 & 4.37 & 5.97 \\
QiaTeKeLe & 4.28 & 6.62 & 3.23 & 4.36 \\
XiaXiang & 4.20 & 6.99 & 4.71 & 5.07 \\
YiLaHu & 4.39 & 6.22 & 6 & 5.54 \\
BoSiTan & 5.39 & 6.18 & 6.25 & 5.96 \\
YaEr & 4.81 & 5.52 & 4.29 & 4.73 \\
YuanZhongChang & 3.38 & 6.30 & 3.27 & 3.99 \\
SanBao & 3.83 & 5.90 & 3.34 & 4.08 \\
YuanYiChang & 4.60 & 4.72 & 5.22 & 4.92 \\
221th state farm & 5.09 & 6.29 & 4.61 & 5.14 \\
\hline
\end{tabular}

\section{Discussion}

Analysis of vulnerability evaluation results

Through comprehensive evaluation, it can be concluded that an effective evaluation result was only produced by multi-indexing. This observation indicates that the degree of vulnerability is decided by pressure, sensitivity, and stability. If a certain area has a higher sensitivity but the ambient pressure is relatively low, then its vulnerability will not manifest. For example, ErBao (located east of the oasis) has a high ground water level and intense evaporation; thus, the sensitivity index reached 6.03. However, because ErBao has high vegetation coverage and rich landscape diversity, the stability of the system was improved, offsetting the vulnerability resulting from sensitivity. Therefore, only a comprehensive evaluation engenders a complete and accurate understanding of the ecological vulnerability (Gao et al. 2013).

The index system for ecological vulnerability evaluation constructed in the study is comparatively complete compared with other vulnerability studies of arid regions. The indexes include ecological (natural and social) pressure, ecological sensitivity, and ecological stability, particularly the desertification index and salinization indexes, as a reflection of the most serious environmental problems in arid regions and factually reflect the ecological vulnerability of the oasis. This comprehensiveness provides a distinct advantage compared with other ecological vulnerability evaluation studies. The index system can also be applied to vulnerability research in similar regions, particularly arid regions. Moreover, the assessment method adopted in this study differs from the conventional method, using the administrative region (Shi et al. 2007; Zhou et al. 2011) or the grid as the assessment unit ( $\mathrm{Li}$ et al. 2006). The administrative regions and raster units were combined in this study. Spatial analysis based on a GIS approach was applied to conduct spatial interpolations and operations, and it extended all of the indexes to the same spatial scale to acquire the same resolution. Therefore, the vulnerability characteristic of any location in the study area can be obtained. This is beneficial for ecological restoration and reconstruction. However, the evaluation results are somewhat subjective because of the weight determined by the AHP method. In further studies, other vulnerability evaluation methods such as the fuzzy evaluation method and artificial neural network can be applied to ensure more objective results.

The effect of land use on ecological vulnerability

Land use and land cover are the main determinants of the structure, function, and dynamics of most landscapes throughout the world (Wu and Hobbs 2002; Li et al. 2007). Changes in land use, particularly in ecologically important land use categories, may significantly affect ecosystem processes and services. Studies on the relationship between vulnerability and land use may help ensure reasonable land use planning. The percentage of different land use areas occupied by each vulnerability level was calculated, and then found that ecological vulnerability is closely related to land use type in the study area. The desertification area increased from 17.75 to $96.31 \%$ along with increasing vulnerability levels (Table 9), but all other types of land showed a decreasing trend. Desertification areas were positively correlated with the degree of vulnerability. To further indicate the relationship between desertification and vulnerability, the value of the desertification index with the 
Fig. 5 Distribution of ecological vulnerability in the study area

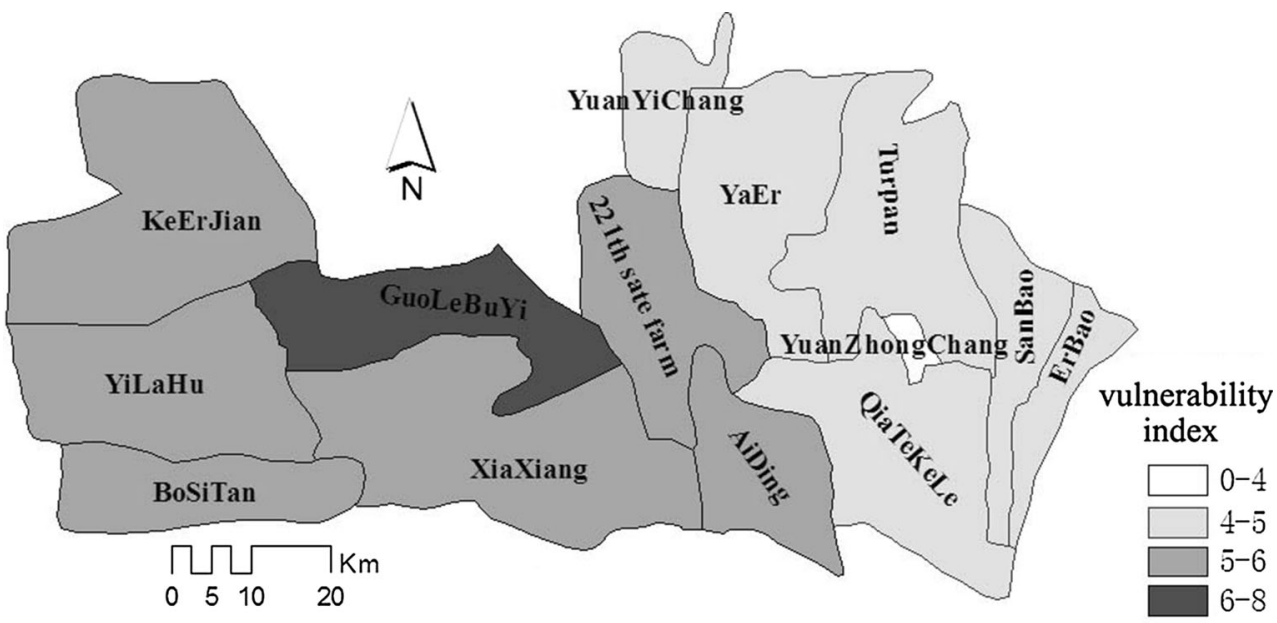

value of the vulnerability index of each town were compared. The analysis showed that the towns with the most serious vulnerability, such as GuoLeBuYi, BoSiTan, and AiDing, all have the highest desertification degree. Desertification plays a key role in the formation of ecological vulnerability. Through remote sensing classification, it can be found that wind erosion desertification and salinization were the main desertification types in the study area. Moderate wind erosion desertification was located on the edge and the periphery of the oasis, which accounted for $64.05 \%$ of the total research area. Salinization land, mild and serious wind erosion desertification types were located in the inner portion of the oasis and accounted for 6.6, 7.58, and $2.23 \%$ of the total research area, respectively. Thus, desertification is extensive in the study area, and ecological restoration and reconstruction are urgently needed.

\section{Ecological restoration and reconstruction measures}

Environmental changes caused by human activities and regional climate changes have long been recognized throughout the world (Gonzalez et al. 2010; Hoegh-Guldberg and Bruno 2010). The formation of vulnerable environments in northwestern China is a result of long-term natural evolution, which has been strongly influenced by human activities in recent times (Zhou et al. 2011). The vulnerability of the Turpan Oasis is also caused by the natural fragility of geological, geomorphic, climatic, and hydrological conditions (Fang et al. 2010). Negative influences of human activities, such as excessive reclamation, overgrazing and improper use of water resources, also increases the pressure on the ecological environment.

According to vulnerability grading results (shown in Fig. 5), the following ecological restoration and reconstruction measures were suggested: (1) In moderately vulnerable regions, which account for $80 \%$ of the total area, the development of agriculture and husbandry should be restricted because of the strong wind erosion, desertification, and salinization sensitivity, as well as the low landscape diversity and vegetation coverage. In serious desertification regions such as Tuokexun and the area near Kumutager Desert, surveys of the soil and water resources should be conducted, and the ecological water use should be monitored to maintain natural ecological conditions. In desert-spreading regions such as ErBao, natural vegetation should be strictly protected and windbreaks should be built to avoid desert sprawl. In serious salinization regions near AiDing Lake, such as AiDing and QiaTeKeLe, it is necessary to reduce water usage withdrawn from rivers and to use groundwater conservatively. In addition, irrigation techniques should be improved to reduce water consumption. (2) In seriously vulnerable regions such as GuoLe$\mathrm{BuYi}$, land degeneration is severe due to wind erosion, grassland degeneration, and secondary salinization of soil. An ecosystem may be more stable if its vegetation cover is high and be more vulnerable when its vegetation cover is low (Wu and Ci 2002). Therefore, it is more important to enforce measures to maintain a stable and high vegetation cover. The desert vegetation in this area should be strictly preserved and the destroyed vegetation should be rebuilt over time. Logging and reclamation of forest areas should be strictly forbidden. Moreover, measures should be taken to control grazing activities in nature reserves to ensure the growth of natural desert vegetation, such as H. ammodendron. (3) The rational use of water resources in the entire region is urgently required, and ensuring ecological water use is critical for ecological construction. Water resource development and utilization are indispensable for ecological restoration in hyper-arid oasis habitats. In the Turpan Oasis, water resource shortages are responsible for many ecological problems. Fang et al. (2010) indicated that the available average amount of annual water resources is $10.9 \times 10^{8} \mathrm{~m}^{3}$ (excluding recycling and reuse of water resources), whereas the ecological and agricultural water 
Table 9 Percentage of the area of different land use types in each vulnerability grade of the environment

\begin{tabular}{lccl}
\hline & Light vulnerability & Moderate vulnerability & Serious vulnerability \\
\hline Farmland & 55.73 & 8.68 & 0 \\
Urban construction land & 0.44 & 0.31 & 0 \\
Desertification land & 17.75 & 80.88 & 96.31 \\
Water & 10.32 & 0.13 & 0 \\
Forestland & 2.00 & 2.49 & 0 \\
Grassland & 13.76 & 7.51 & 3.69 \\
\hline
\end{tabular}

requirements are $11.204 \times 10^{8} \mathrm{~m}^{3}$, which thus exceeds the available amount of water resources. It is anticipated that the water requirements will further increase in the future. With the expansion of irrigated areas in the oasis, it will be more difficult to guarantee the amount of ecologically available water, which might lead to further deterioration and degradation of the ecological environment. According to the economic and environmental characteristics of the Turpan Oasis, the following strategies for the utilization of water resources were suggested. First, the use of ecological water and water for sustenance should be ensured. Second, the use of irrigation water should be reduced, and virtual water imports for agriculture should be improved. The adjustment of planting structures is also an important measure to conserve agricultural water in addition to watersaving irrigation techniques. Third, water resource quotas should be appropriately increased for industry sectors, including the tourist industry.

\section{Conclusions}

This paper evaluated vulnerability as a comprehensive reflection of the stability, sensitivity, and degree of pressure of the ecological environment and organized the characteristics into 16 indexes, including desertification, ground water level, and population density, to construct a comprehensive evaluation model for ecological vulnerability research in typical arid oasis areas, which is a significant potential for providing insights on ecological vulnerability evaluation. A remote sensing classification method-decision tree classification was applied to SPOT-5 data with a resolution of $10 \mathrm{~m}$; next, the land use and land cover information, particularly desertification, was extracted, and the methods used in this paper can serve as a guidance for regions which lack collected data. According to the assessment results, the conclusions are as follows:

1. Wind erosion desertification and saline land account for $80.88 \%$ of the total area. The degree of desertification in the study area is very high, and the desertification has aggravated the ecological vulnerability. The moderately vulnerable region accounts for $81.85 \%$ of the total area, and the light and serious vulnerability regions account for 4.19 and $13.95 \%$, respectively, of the total area. More than $80 \%$ of the area has reached moderate vulnerability, and nearly $14 \%$ of the area has reached serious vulnerability. Desertification areas are positively correlated with degree of vulnerability. The desertification area increased from 17.75 to $96.31 \%$ along with increasing vulnerability levels, but all other types of land showed a decreasing trend.

2. The rational use of water resources in the entire region is urgently required and the availability of ecological water use is critical for ecological construction. First, ecological water use and water for sustenance should be prioritized. Second, irrigation water efficiency should be improved. Importing water-intensive agricultural products is an effective measure to reduce irrigation water use. Shifting water-intensive crop structure into less-water-used crop structure is another alternative option to save irrigation water. Third, water use quotas should be adjusted from agriculture to industry and services (particularly the tourist industry). This measure will increase the economic efficiency of water use.

Acknowledgments The authors thank all the team members' wholehearted participation in this work, and also are grateful to anonymous referees and associate editors for their thoughtful suggestions on the manuscript, which has led to improvements in this paper. This study was supported and funded by the "National Basic Research Program of China (973 Program) (grant no 2010CB951504)", the "Natural Science Foundation of Hebei Province (grant no D2014203218), the "Yong Teacher's Independent Research Project of Yanshan University (grant no 14LGA011), and the "National Natural Science Foundation of China (grant no 41201097)".

\section{References}

Antonio GS, Juan-Alfonso B, Nicolau J (2003) Assessing landscape values: a proposal for a multidimensional conceptual model. Ecol Model 168:319-341. doi:10.1016/S0304-3800(03)00144-3

Aryafar A, Yousefi S, Ardejani FD (2013) The weight of interaction of mining activities: groundwater in environmental impact assessment using fuzzy analytical hierarchy process (FAHP). Environ Earth Sci 68(8):2313-2324. doi:10.1007/s12665-0121910-x 
Aspinall R, Pearson D (2000) Integrated geographical assessment of environmental condition in water catchments: linking landscape ecology, environmental modeling and GIS. J Environ Manage 59(4):299-329. doi:10.1006/jema.2000.0372

Babiker IS, Mohamed MA, Hiyama T, Kato K (2005) A GIS-based DRASTIC model for assessing aquifer vulnerability in Kakamigahara Heights, Gifu Prefecture, central Japan. Sci Total Environ 345(1):127-140. doi:10.1016/j.scitotenv.2004.11.005

Bagdanavičiūtė I, Valiūnas J (2013) GIS-based land suitability analysis integrating multi-criteria evaluation for the allocation of potential pollution sources. Environ Earth Sci 68(6): 1797-1812. doi:10.1007/s12665-012-1869-7

Benjamin MT, Daniel OC, Dimas MF (2013) Financial fragility in a general equilibrium model: the Brazilian case. Ann Finance 9(3):519-541. doi:10.1007/s10436-012-0199-9

Bi CJ, Chen ZL, Wang J, Zhou D (2013) Quantitative assessment of soil health under different planting patterns and soil types. Pedosphere 23(2):194-204

Chatterjee S, Krishna AP, Sharma AP (2014) Geospatial assessment of soil erosion vulnerability at watershed level in some sections of the Upper Subarnarekha river basin, Jharkhand, India. Environ Earth Sci 71(1):357-374. doi:10.1007/s12665-0132439-3

Duguy B, Alloza JA, Baeza MJ, De la Riva J, Echeverría M, Ibarra P, Llovet J, Cabello FP, Rovira P, Vallejo RV (2012) Modelling the ecological vulnerability to forest fires in mediterranean ecosystems using geographic information technologies. Environ Manage 50(6):1012-1026. doi:10.1007/s00267-012-9933-3

Dzeroski S (2001) Applications of symbolic machine learning to ecological. Ecol Model 146:263-273. doi:10.1016/S0304-3800 (01)00312-X

Fang SF, Pei H, Beven KJ, Liu ZH, Wei ZC (2010) Water resources assessment and regional virtual water potential in Turpan basin, China. Water Resour Manag 24(13):3321-3332. doi:10.1007/ s11269-010-9608-x

Farshad R, Safavi HR, Ahmad AI (2013) Groundwater vulnerability assessment using fuzzy logic: a case study in the Zayandehrood Aquifers, Iran. Environ Manage 51(1):267-277. doi:10.1007/ s00267-012-9960-0

Fuchs S, Birkmann J, Glade T (2012) Vulnerability assessment in natural hazard and risk analysis: current approaches and future challenges. Nat Hazards 64(3):169-1975. doi:10.1007/s11069012-0352-9

Gao C, Lei J, Jin FJ (2013) The classification and assessment of vulnerability of man-land system of oasis city in arid area. Front Earth Sci 7(4):406-416. doi:10.1007/s11707-013-0402-y

Gonzalez P, Neilson RP, Lenihan JM, Drapek RJ (2010) Global patterns in the vulnerability of ecosystems to vegetation shifts due to climate change. Global Ecol Biogeogr 19(6):755-768. doi:10.1111/j.1466-8238.2010.00558.x

Hoegh-Guldberg O, Bruno JF (2010) The impact of climate change on the world's marine ecosystems. Science 328(5985): $1523-1528$

Huang PH, Tsai JS, Lin WT (2010) Using multiple-criteria decisionmaking techniques for eco-environmental vulnerability assessment: a case study on the Chi-Jia-Wan Stream watershed Taiwan. Environ Monit Assess 168(1):141-158. doi:10.1007/ s10661-009-1098-z

Hufschmidt G (2011) A comparative analysis of several vulnerability concepts. Nat Hazards 58(2):621-643. doi:10.1007/s11069-0119823-7

Ippolito AS, Sala JH, Faber MV (2010) Ecological vulnerability analysis: a river basin case study. Sci Total Environ 408(18): 3880-3890. doi:10.1016/j.scitotenv.2009.10.002

Kangas J, Store R, Leskinen P, Mehtätalo L (2000) Improving the quality of landscape ecological forest planning by utilizing advanced decision-support tools. For Ecol Manag 132(2): 157-171. doi:10.1016/S0378-1127(99)00221-2

Khan S (2012) Vulnerability assessments and their planning implications: a case study of the Hutt Valley, New Zealand. Nat Hazards 64(2):1587-1607. doi:10.1007/s11069-012-0327-x

Kia MB, Pirasteh S, Pradhan B, Mahmud AR, Sulaiman WA, Moradi A (2012) An artificial neural network model for flood simulation using GIS: Johor River Basin, Malaysia. Environ Earth Sci 67(1):251-264. doi:10.1007/s12665-011-1504-z

Lashkari A, Bannayan M (2012) Agrometeorological study of crop drought vulnerability and avoidance in northeast of Iran. Theor Appl Climatol 109(2):27-38. doi:10.1007/s00704-012-0769-9

Li A, Wang A, Liang S, Zhou W (2006) Eco-environmental vulnerability evaluation in mountainous region using remote sensing and GIS-A case study in the upper reaches of Minjiang River, China. Ecol Model 192:175-187. doi:10.1016/j.ccolmo del.2005.07.005

Li RQ, Dong M, Cui JY, Zhang LL, Cui GQ, He WM (2007) Quantification of the impact of land use and land cover changes on ecosystem services: a case study in Pingbian County, China. Environ Monit Assess 128(1):503-510. doi:10.1007/s10661006-9344-0

Manfre LA, da Silva AM, Urban RC, Rodgers J (2013) Environmental fragility evaluation and guidelines for environmental zoning: a study case on Ibiuna (the Southeastern Brazilian region). Environ Earth Sci 69(3):947-957. doi:10.1007/s12665-0121979-2

Mao XY, Meng JJ, Xiang YY (2013) Cellular automata-based model for developing land use ecological security patterns in semi-arid areas: a case study of Ordos, Inner Mongolia, China. Environ Earth Sci 70(1):269-279. doi:10.1007/s12665-012-2125-x

Moreno A, Becken S (2009) A climate change vulnerability assessment methodology for coastal tourism. J Sustain Tour 17(4):473-488. doi:10.1080/09669580802651681

Ramezani H, Holm S (2011) Sample based estimation of landscape metrics; accuracy of line intersect sampling for estimating edge density and Shannon's diversity index. Environ Ecol Stat 18(1):109-130. doi:10.1007/s10651-009-0123-2

Saidi S, Bouri S, Dhia HB (2010) Groundwater vulnerability and risk mapping of the Hajeb-jelma aquifer (Central Tunisia) using a GIS-based DRASTIC model. Environ Earth Sci 59(7):1579-1588. doi:10.1007/s12665-009-0143-0

Salvati L, Tombolini I, Perini L, Ferrara A (2013) Landscape changes and environmental quality: the evolution of land vulnerability and potential resilience to degradation in Italy. Reg Environ Change 13(6):1223-1233. doi:10.1007/s10113-013-0437-3

Santos CF, Carvalho R, Andrade F (2013) Quantitative assessment of the differential coastal vulnerability associated to oil spills. J Coast Conserv 17(1):25-36. doi:10.1007/s11852-012-0215-2

Scheuer S, Haase D, Meyer V (2011) Exploring multicriteria flood vulnerability by integrating economic, social and ecological dimensions of flood risk and coping capacity: from a starting point view towards an end point view of vulnerability. Nat Hazards 58(2):731-751. doi:10.1007/s11069-010-9666-7

Shao HY, Liu M, Shao QF, Sun XF, Wu JH, Xiang ZY, Yang WN (2014) Research on eco-environmental vulnerability evaluation of the Anning River Basin in the upper reaches of the Yangtze River. Environ Earth Sci 72(5):1555-1568. doi:10.1007/s12665014-3060-9

Shi Q, Lu ZH, Liu ZM, Miao Y, Xia MJ (2007) Evaluation model of the grey fuzzy on eco-environment vulnerability. J For Res-Jpn 18(3):187-192. doi:10.1007/s11676-007-0038-4

Shi HD, Gao QX, Qi YQ, Liu JY, Hu YF (2010) Wind erosion hazard assessment of the Mongolian Plateau using FCM and GIS techniques. Environ Earth Sci 61:689-697. doi:10.1007/s12665009-0381-1 
Song GB, Chen Y, Tian MR (2010) The ecological vulnerability evaluation in southwestern mountain region of China based on GIS and AHP method. Pro Environ Sci 2:465-475. doi:10.1016/ j.proenv.2010.10.051

Sullivan C (2011) Quantifying water vulnerability: a multi-dimensional approach. Stoch Env Res Risk 25(4):627-640. doi:10. 1007/s00477-010-0426-8

Tasser E, Sternbach E, Tappeiner U (2008) Biodiversity indicators for sustainability monitoring at municipality level: an example of implementation in an alpine region. Ecol Indic 8(3):204-223. doi:10.1016/j.ecolind.2007.01.005

Walz U (2015) Indicators to monitor the structural diversity of landscapes. Ecol Model 295:88-106. doi:10.1016/j.ecolmodel. 2014.07.011

Walz U, Syrbe RU (2013) Linking landscape structure and biodiversity. Ecol Indic 31:1-5. doi:10.1016/j.ecolind.2013.01.032

Wan L, Xia J, Hong S, Bu HM, Ning LK, Chen JX (2014) Decadal climate variability and vulnerability of water resources in arid regions of Northwest China. Environ Earth Sci. doi:10.1007/ s12665-014-3874-5

Wang SY, Liu JS, Yang CJ (2008) Eco-environmental vulnerability evaluation in the Yellow River Basin, China. Pedosphere 18(2):171-182. doi:10.1016/S1002-0160(08)60005-3
Watts MJ, Bohle HG (1993) The space of vulnerability: the causal structure of hunger and famine. Prog Hum Geogr 17:43-47. doi: $10.1177 / 030913259301700103$

Wu B, Ci LJ (2002) Landscape change and desertification development in Mu Us Sandland, Northern China. J Arid Environ 50(3):429-444. doi:10.1006/jare.2001.0847

Wu J, Hobbs R (2002) Key issues and research priorities in landscape ecology: an idiosyncratic synthesis. Landsc Ecol 17(4):355-365. doi:10.1023/A:1020561630963

Yoo G, Hwang JH, Choi C (2011) Development and application of a methodology for vulnerability assessment of climate change in coastal cities. Ocean Coast Manage 54(7):524-534. doi:10.1016/ j.ocecoaman.2011.04.001

Zhou XL, Yan Y, Wang H, Wu LY, Ren JZ (2011) Assessment of eco-environment vulnerability in the northeastern margin of the Qinghai-Tibetan Plateau, China. Environ Earth Sci 63(4): 667-674. doi:10.1007/s12665-010-0731-z

Zou XP, Pang YX, Zhu HL (2013) The study between shadow banking and financial fragility in China: an empirical analysis based on the co-integration test and error correction model. Qual Quant 47(6):3363-3370. doi:10.1007/s11135-012-9725-0 